\title{
EDUCATIONAL SUPERVISION: A THEORETICAL PERSPECTIVE
}

\author{
Anangahana Das \\ Research Scholar, Department of Education, \\ Dibrugarh University, India
}

\begin{abstract}
The concept of educational supervision has passed through several developmental stages and has now been conceived in a more democratic outlook. In the present period of Information technology (IT), which has now revolutionized the whole education process, supervision becomes a major instrument to ensure quality and to develop the standard of education. Presently, the scope of educational supervision is widened to comprehend the functions of an educational institution in the role of supervisors, upgrading the institution to facilitators in the process. The purpose of this paper is to study the different theoretical aspects contributing to this modern concept of educational supervision. In this paper, the researcher discusses educational supervision with respect to its objectives, types and functions. This will throw light on the theoretical perspectives of modern educational supervision.
\end{abstract}

Key words: Theoretical, perspective, education, modern, supervision

Cite this Article: Anangahana Das, Educational Supervision: A Theoretical Perspective, International Journal of Management, 11(12), 2020, pp 982-987.

http://iaeme.com/Home/issue/IJM?Volume=11\&Issue=12

\section{INTRODUCTION}

Educational administration and supervision are now considered as a total process inclusive of all responsibilities and functions necessary for running an educational administration. Good interpersonal relationships between the administrator and the supervisor, the supervisor and teachers, teachers and students and also inter institutional relationships between school and state, school and community, group dynamics, etc. are receiving greater emphasis. All these factors have resulted in a new philosophy, according to which administration is concerned with managing resources, allocating tasks, making decisions and solving problems and supervision is concerned with their improvement as well as that of the whole teachinglearning situation. In modern educational thought, supervision is a phase of administration with particular emphasis on the products of teaching and learning activities. Defining educational supervision: Educational supervision is defined as the process of providing facilities for students and to train teachers in order to make children better learners. Supervision is combination of two words 'super' which means "above or over" and 'vision' 
means "to see". Thus, supervision means overseeing and directing the works of others. Therefore it can also be defined as the efforts to stimulate, co-ordinate and guide the continuous development of teachers as well as other educational workers in an educational institution, both individually and collectively for improvement of all the functions of the institution. Supervision can be understood as a form of technical support and service that is being offered to assist teachers to perform their work in an improved manner.

Walls defines supervision as "Assistance provided for the advancement of a better teaching and learning circumstances".

According to Bigs and Justman "In general, supervision means to coordinate, stimulate and direct the growth of the teachers in the power to stimulate and direct the growth of every individual pupil through the exercise of his talents towards the richest and the most intelligent participation in the civilization in which he lives."

Supervision, however, does not imply inquiring or finding fault in a performance. It is

a method of providing guidance, support and exchanging of ideas with all the people

involved in the process of teaching and learning. It also means to provide facilities, to encourage creativity and a constant improvement of a conductive teaching-learning environment. Supervision is about assisting the teachers and also the learners to recognize and implement their capacities in their respective fields of work.

\section{OBJECTIVES}

1. To study the different theoretical aspects of educational supervision.

\section{METHODOLOGY}

The present study is based on secondary data. Data has been collected from books, journals, news, letter, websites etc.

\section{DISCUSSION}

Objective wise discussion has been done below:

\subsection{Objectives of Educational Supervision}

The objectives of supervision can be listed as follows:

To unify and integrate educational effort : Supervision must be prepared with the aim of coordinating different available resources and materials that are available simultaneously by combining and integrating the efforts put in by the entire staff .

To improve knowledge and skills of teachers: The planning for supervision revolves around the work, the philosophy and the approach of the teachers. In order to accomplish the majority of the school's work efficiently, the teachers must learn to work together in groups and one of the major objectives of supervision is the enhancement of teacher's skills in working in a cooperative manner.

To incorporate new trends: In order to accomplish an improvement in the delivery and understanding of instructions, the school practices which are followed need to be updated with the changes in contemporary educational thinking and practice. It is the responsibility of the supervisor to help the educational workers to keep abreast of the new educational movements, to study and learn new methods of teaching and to apply these new techniques in the classroom situations.

Improvement of teaching -learning situation: The main objectives of supervision is the evaluation and development of the teaching learning situation. The objectives of democratic 
supervision are the evaluation and development of the teaching -learning situation. The objectives of democratic supervision are to help teachers to evaluate themselves with the help of inputs given by supervisor. The prime constituents of the teaching -learning process are the students, teachers, curriculum materials and information, classroom management, and the socio physical environment.

Promotion of good relationship: For achieving complete effectiveness, supervision depends upon the relation that exists between teachers and the supervisors. In order to accomplish most of the schools work, the teachers must learn to work with cooperation and that can only be possible if they share a good relation with the supervisor. One of the objectives of supervision is the enhancement of good interpersonal relations. For effective and efficient supervisions, healthy relationship must be developed and maintained between supervisor administrator, teacher- supervisor, and administrators -teachers.

\subsection{Types of Educational Supervision}

Programmes could be conducted in various ways. The three types of educational supervision are as follows -

Corrective Type: The purpose of employing this type of supervision does not have any beneficial function. In the corrective supervision, the supervision always tries to find loopholes and shortcomings in everything. He takes into account only the drawbacks of the teacher, the classroom situation, the institution, and so on. He rarely provides any recommendations for improvement. He takes into account only the drawbacks and shortcomings, and even more eager to bring them to the notice of the concerned authorities. But a supervisor must remember that the progress depends on a judicious combination of encouragement of good work and removal of defects.

Advantages of corrective type of supervision are -

1. Teachers and students pay more emphasis on regularity and punctuality as they are aware that they are under supervision that they will be checked and evaluated by the supervisor.

2. Everyone in the institution becomes conscious of their shortcomings and tries to overcome them by coming well prepared.

Disadvantages of corrective supervision are -

1. It discourages the teachers as they are under supervision all the time. Therefore, it is not a healthy type of supervision.

2. Teachers attain a negative attitude which is detrimental for the teaching learning process.

3. Teachers and learners fail to do their duties with enthusiasm and vitality which results in lack of growth. There is no thriving of a creative academic climate in the school.

Preventive Type: In this category of supervision, the teachers and the principals are themselves able to prevent troubles and problems. Preventive supervision paves the path for the teachers to expect and predict new teaching situations and find suitable methods and means to eliminate any kind of deficiencies. Being an experienced person, the supervisor can foresee all type of problems that can arise during the functioning of schools. But for such a supervision to be successful, the supervisors needs to be extremely well trained.

Advantages of preventive supervision are -

1. The jobs of teachers and of the head become easy as the solutions for the problems are thought beforehand.

2. It helps in the development of outstanding qualities in teachers like imagination and forecasting, appropriate planning and being solution oriented and so on. The teaching learning procedure becomes more beneficial. 
Disadvantages of preventive supervision are-

1. Thee teachers have to lookout for all kind of problems that may arise and be ready with their possible solutions before and during the process of teaching. Hence, their workload increase and they are under more pressure.

2. If the supervisors aren't well trained in forecasting and predicting, the supervision process may not be at all effective and lead to wastage of time and resources.

3. The teachers may fail to become creative a their whole focus is o problems.

Creative Type: In creative supervision the supervisor brings himself down to the level of working of the teachers. He acknowledges the good work of the teachers who take initiatives and try to be innovative and experiment in the area of education. The impact of creative supervision on the teachers is very healthy and durable. It motives them to feel free to initiative and innovate; they can themselves think and decide about matters related to objectives, curriculum, organization and planning of content, and discover the optimum ways of learning and presenting content, teaching methods and methods of evaluation.

The advantages of creative supervision are.

1. It makes teachers creative and research - minded. Teachers become independent and feel motivated to do their job without much pressure.

2. It provides a healthy social climate and is a great tool to handle the prevailing problems.

3. Creativity and an attitude of innovation and experimentation opens the way for progressive leaps in the educational process.

A disadvantage of creative supervision is that there is a great possibility of the misuse of freedom being provided, thus hampering the efficient functioning.

\subsection{Functions of Educational Supervision}

There are numerous functions which have been performed by supervision. Offering leadership, formulation of policies, study of teaching -learning situations and recognizing the areas which need improvement and providing methods for the same, are some important functions of supervision. It also assists in improving the interrelation personnel, group interaction and outcome of education.

1. Improvement of Teaching Learning Situation: With proper planning and the cooperation among all workers, supervision undertakes constructive steps for the development of the teaching -learning situation. Instructions should be modulated according to the individual needs of the learners. The course of teaching should be revised regularly. It should be lifecentred, i.e., related to the character and requirements of the learners and factors related to their current family and community life. Teachers must be kept updated of the latest researches and developments in education.

2. Providing Leadership: Leadership may be defined as the process of conception and attainments of the goals and objectives of the group. Without leadership both the actions and cohesiveness of the group are in danger. For the group to be successful, it is crucial to maintain harmony within the group. Thus, one of the most significant functions of supervision is to provide leadership that will maintain the unity of the group by the promotion of group feelings and group efforts. Democracy is an important factor which influences supervision. Thus, any member of the group who is capable can exercise leadership.

3. Development of Goal: The most important function of supervision is to make sure that teachers and supervisors work together in coordination towards the objectives of the school organization. It is important to note that the objectives of a school originate from the 
objectives of the society. Also the development of goals for the teaching-learning process needs collective efforts from both the teachers and the supervisors.

4. Improving Human Relations: One of the major functions of supervision is to conceive and maintain a cordial inter-personal relation with and among all the educational workers. A congenial relationship cannot be achieved by merely bringing people together to form a group: it can only be created by living and working with the staff members in such a manner that they can implement good human relations. A supervisor must take care of his co workers as his colleagues.

5. Improving group interaction: Education is a cooperative group enterprise. An important function of supervision is to develop and maintain cooperation with the staff and this canbe achieved by promoting group efforts. Group work encourages individual development, strengthens democratic practices and fosters moral and ethical values. It also enables each group members to contribute their best to collective efforts towards the achievements of desired goals. It is important that group members know each other's duties and responsibilities in order to have a better group interaction. Decisions must be taken only after group discussion.

6. Improving the outcome of education: The education process is initiated and implemented in order to attain certain general as well as specific goals and objectives. Educational practices should continuously improve the educational outcomes. An institute mainly endorses supervision in order to improve the results of education. Supervision should constantly recognize the strengths and weaknesses of the educational programmes and identify the areas of improvement, if necessary. It should also adopt methods to rectify the shortcomings as and when needed.

7. Improving supervision: It may sound strange that supervision could function for its own improvement but if we consider that supervision defines its own intentions and methods, it is therefore capable to assess frequently whether or not and to what extent it fulfils the allotted functions. This involves self appraisal of its results or outcomes, amendments in its methodology and procedures as well as developments of the supervisory personnel. Modern supervision thus emphasizes that teachers and supervisors should make efforts towards selfdirection, self evaluation, self guidance and self- supervision.

8. Improving morale of teachers: It is a very essential for a supervisor to understand the importance of confidence and morale in teaching learning situation and develop methods to improve it. Morale is an attitude towards the achievement of a goal. Morale is considered as a psychological state of mind which develops as a consequence of the way an individual perceives his present achievement and progress. A teacher with a low morale does great harm to his students, as this attitude results in constant criticizing of authorities, policies and programmes, throwing temper tantrums and warding -off responsibility. An important function of supervisor is make sure that the psychological framework of the teachers is positive and in line with the organizational objectives.

9. Development of Motivation: It is only through a highly motivated faculty that an educational institution can expect to facilitate students learning in the right direction. One important outcome of supervision is therefore assumed to be enhancement of motivation of both teachers and the supervisors through their interaction to work towards the achievement of the goals of education.

10. Problem Solving: The facilitation of human problem solving is another function of supervision. Educational instructions require a constant process of examining for achieving the desired outcomes. Failure to achieve, demands new attempts with new ideas. It requires capacity of problem solving with regard to specification of goals, re-arranging the conditions for achieving goals, where supervision makes intervention for helping in this regard. 


\section{CONCLUSION}

Supervision, as a process brings all these facets into a fruitful and harmonious whole, in order to ensure an optimum teaching- learning environment. It becomes a major instrument to ensure quality and to develop the standard of education. Lastly it can be concluded by saying that Educational Supervision is thus, an old concept with new meanings at all phases of its evolution. However development of the educational programmes has always been the ultimate goal of Educational Supervision. The different theoretical aspects of supervision, discussed so far, clearly depicts the basic nature of modern supervision, presently prevailing around the world. Modern educational supervision has a democratic outlook and its co-operative and comprehensive nature encompasses the students, teachers, administrators, parents and all other concerned with the machinery of educational institutions, under its roof, making it an integral organ of the body of Education.

\section{REFERENCES}

[1] Bala R. Educational Supervision, Theories and Practices. New Delhi: Alfa Publications, 2012.

[2] Best JW, Kahn JV. Research in Education. New Delhi: PHI Learning Private Limited 2012.

[3] Bhatt BD, Sharma SR. Educational Supervision: Theory and Practice. New Delhi: Kanishka Publishing House, 1992.

[4] Brigg TH, Justman J. Improving Instruction Through Supervision. New York: The Macmillan Company, 1952.

[5] Burton WH, Brueckner LJ. Supervision: A Social Process. New York: Appleton -Century Crofts, 1955.

[6] Dougloss HR, Bent R , Boardman CW. Democratic Supervision in Secondary Schools. Boston: Houghton Mifflin Harcourt, 1961.

[7] Koul L. Methodology of Educational Research. Noida: VIKAS Publishing House Pvt. Ltd, 2014.

[8] Lovell J. Supervision: Perspectives and Propositions. Washington DC. Association for Supervision and Curriculum Development, 1967.

[9] Mohanty B. School Administration and Supervision. New Delhi: Deep \& Deep Publications Pvt. Ltd, 2007.

[10] Mohanty J. Educational Management, Supervision and School Organisation. New Delhi: Neelkamal Publications Pvt. Ltd, 2012.

[11] Sullivan S, Glanz J. Supervision that Improves Teaching: Strategies and Techniques. Thousand Oaks, California: Corwin Press Inc, 2000.

[12] Thakral S. The Historical Context of Modern Concept of Supervision. Journal of Emerging Trends in Educational Research and Policy Studies. 2015; 6(1):79 -88.

[13] Tracy ST. How Historical Concepts of Supervision Relate to Supervisory Practices Today. The Clearing House, Retrieved from http://www.jstor.org/stable/30189094 DoR . 1995 -2016; 68(5):320 -325 